\title{
Tailoring Cu Nanoparticle Catalyst for Methanol Synthesis Using the Spinning Disk Reactor
}

\author{
Christian Ahoba-Sam ${ }^{1}$ (D), Kamelia V. K. Boodhoo ${ }^{2}$, Unni Olsbye ${ }^{3}$ and Klaus-Joachim Jens ${ }^{1, *}$ \\ 1 Department of Process, Energy and Environmental Technology, University College of Southeast Norway, \\ Kjølnes Ring 56, 3918 Porsgrunn, Norway; christian.ahoba-sam@usn.no \\ 2 School of Engineering, Merz Court, Newcastle University, Newcastle Upon Tyne NE1 7RU, UK; \\ kamelia.boodhoo@newcastle.ac.uk \\ 3 Department of Chemistry, University of Oslo, P.O. Box 1033, Blindern, N-0315 Oslo, Norway; \\ unni.olsbye@kjemi.uio.no \\ * Correspondence: Klaus.J.Jens@usn.no; Tel.: +47-3557-5193
}

Received: 22 December 2017; Accepted: 15 January 2018; Published: 17 January 2018

\begin{abstract}
Cu}$ nanoparticles are known to be very active for methanol $(\mathrm{MeOH})$ synthesis at relatively low temperatures, such that smaller particle sizes yield better $\mathrm{MeOH}$ productivity. We aimed to control $\mathrm{Cu}$ nanoparticle (NP) size and size distribution for catalysing $\mathrm{MeOH}$ synthesis, by using the spinning disk reactor. The spinning disk reactor (SDR), which operates based on shear effect and plug flow in thin films, can be used to rapidly micro-mix reactants in order to control nucleation and particle growth for uniform particle size distribution. This could be achieved by varying both physical and chemical operation conditions in a precipitation reaction on the SDR. We have used the SDR for a $\mathrm{Cu}$ borohydride reduction to vary $\mathrm{Cu} N P$ size from $3 \mathrm{~nm}$ to about $55 \mathrm{~nm}$. XRD and TEM characterization confirmed the presence of $\mathrm{Cu}_{2} \mathrm{O}$ and $\mathrm{Cu}$ crystallites when the samples were dried. This technique is readily scalable for $\mathrm{Cu}$ NP production by processing continuously over a longer duration than the small-scale tests. However, separation of the nanoparticles from solution posed a challenge as the suspension hardly settled. The $\mathrm{Cu}$ NPs produced were tested to be active catalyst for $\mathrm{MeOH}$ synthesis at low temperature and $\mathrm{MeOH}$ productivity increased with decreasing particle size.
\end{abstract}

Keywords: $\mathrm{Cu}$ nanoparticles; spinning disc reactor; methanol synthesis; low temperature

\section{Introduction}

Methanol $(\mathrm{MeOH})$ is a multi-purpose molecule widely used as a base chemical, for energy, and $\mathrm{CO}_{2}$ storage [1]. It is used as a solvent or as an intermediate for the production of formaldehyde, methyl tert-butyl ether, acetic acid, methyl methacrylate, and other fine chemicals. $\mathrm{MeOH}$ can also be used as fuel blend or directly converted to valuable hydrocarbons such as gasoline over acidic microporous materials [2], thereby providing alternative sources of petrochemical feedstock used today.

Currently, the technology for $\mathrm{MeOH}$ synthesis is based on conversion of synthesis gas (composed largely of $2 \mathrm{H}_{2} / \mathrm{CO}$ with about $5 \% \mathrm{CO}_{2}$ ) over $\mathrm{CuO} / \mathrm{ZnO} / \mathrm{Al}_{2} \mathrm{O}_{3}$ catalyst operating at around 250-300 ${ }^{\circ} \mathrm{C}$ and 50-100 bar [3]. Even though this process is highly optimized, the thermodynamics of the reaction limit syngas conversion per pass, which, coupled with other operational costs, make the process capital intensive. For example, more than $60 \%$ of the total capital cost in current $\mathrm{MeOH}$ processes is associated with the syngas plant [4].The lowest cost of syngas production is by the use of air rather than a pure cryogenic $\mathrm{O}_{2}$-blown autothermic reformer [3]. Syngas conversion to $\mathrm{MeOH}$ is highly exothermic (shown in Equation (1)) and lower temperatures are required to achieve full conversion per pass. A full conversion per pass process allows the use of $\mathrm{N}_{2}$ diluted syngas for $\mathrm{MeOH}$ 
production, which implies no need for recycling of unconverted reactants. Consequently, the carbon footprint is reduced [5] as a result of the full conversion.

$$
\mathrm{CO}+2 \mathrm{H}_{2} \rightleftharpoons \mathrm{CH}_{3} \mathrm{OH} \Delta \mathrm{H}=-90.6 \mathrm{~kJ} / \mathrm{mol}
$$

Alternatively, low temperature $\mathrm{MeOH}$ synthesis (LTMS), which proceeds rapidly in liquid medium at about $100^{\circ} \mathrm{C}$ presents the possibility for full syngas conversion per pass [6]. This technology is known to occur in two steps as shown in Equations (2) and (3). The carbonylation of $\mathrm{MeOH}$ to methyl formate (Equation (2)) is catalysed by an alkali alkoxide, while a transition metal based compound catalyses the hydrogenolysis of methyl formate (Equation (3)).

$$
\begin{aligned}
& \mathrm{CO}+\mathrm{CH}_{3} \mathrm{OH} \rightleftharpoons \mathrm{HCOOCH}_{3} \\
& \mathrm{HCOOCH}_{3}+2 \mathrm{H}_{2} \rightleftharpoons 2 \mathrm{CH}_{3} \mathrm{OH}
\end{aligned}
$$

The Cu-based catalyst is one catalyst which has received a lot of attention for LTMS [7-11]. Examples of $\mathrm{Cu}$-based materials reported for the hydrogenolysis reaction include $\mathrm{CuO} / \mathrm{Cr}_{2} \mathrm{O}_{3}$, Raney $\mathrm{Cu}, \mathrm{Cu}$ on $\mathrm{SiO}_{2}, \mathrm{CuCl}_{2}$, and $\mathrm{Cu}$ alkoxide. Prolonged milling of a physical mixture of $\mathrm{CuO}$ and $\mathrm{Cr}_{2} \mathrm{O}_{3}$, for example, enhanced $\mathrm{MeOH}$ synthesis activity [7]. We have also observed that $\mathrm{Cu}$ nanoparticle (NP) sizes influenced $\mathrm{MeOH}$ production, such that $\mathrm{MeOH}$ productivity increased with decreasing the particle size [10]. In both instances, $\mathrm{MeOH}$ productivity correlated well with increasing total surface area. This implies that producing the right-sized $\mathrm{Cu}$ particles as a catalyst for $\mathrm{MeOH}$ synthesis is important. In general, different $\mathrm{Cu}$ NPs sizes can be synthesized by following different experimental protocols and recipes [12]. Based on $\mathrm{MeOH}$ yield dependence on the $\mathrm{Cu}$ NP sizes, an on-purpose physical method for making $\mathrm{Cu}$ NP catalyst of different sizes using a specific chemical recipe will be a valuable contribution. In this work, we will focus on the use of spinning disk reactor (SDR), a technique that can fine-tune the $\mathrm{Cu}$ NP catalyst size for $\mathrm{MeOH}$ synthesis.

The SDR is a continuous-flow process intensification reactor with enhanced production efficiency, safety, minimal cost, and minimal waste technology $[13,14]$. A thin film liquid is formed in the SDR due to centrifugal acceleration created by rotation of the disk. The key characteristics of the thin film flow include rapid mixing, heat and mass transfer, plug flow, and short residence times in the order of seconds [15]. For example, the residence time, $t_{\text {res }}$ of liquid reagents traveling with $\mathrm{Q}$ flow rate, from $r_{i}$ to $r_{o}$ on the disk based on the Nusselt theory can be expressed by Equation (4), where $\mu$ is dynamic viscosity and $\omega$ is angular velocity. Hence, increasing the flow rate and rotation speed for example will lead to a shorter residence time and consequently affect crystallization process.

$$
t_{r e s}=\frac{3}{4}\left(\frac{12 \pi^{2} \mu}{Q^{2} \omega^{2}}\right)^{\frac{1}{3}}\left(r_{o}^{\frac{4}{3}}-r_{i}^{\frac{4}{3}}\right)
$$

The SDR can therefore be employed in sol-gel precipitation processes where homogenous mixing of the reactants at the molecular level is essential for controlling crystallite and particle size. Recently, the SDR has been used in several precipitation reactions for nanoparticles production [13,16-18]. Tai et al. [17], for example, used the SDR to produce $40-50 \mathrm{~nm} \mathrm{CuO}$ nanoparticles using $\mathrm{Cu}\left(\mathrm{SO}_{4}\right)$ and $\mathrm{Na}\left(\mathrm{CO}_{3}\right)_{2}$ as reactants for nanofluid application.

In this work, we have used the SDR to produce different $\mathrm{Cu}$ NP sizes and size distributions, in a more environmentally friendly condition, using aqueous borohydride and $\mathrm{Cu}\left(\mathrm{NO}_{3}\right)_{2}$ as reactants. Our aim was to find out if the SDR could be used to purposefully produce $\mathrm{Cu} N \mathrm{~N}$ catalysts for $\mathrm{MeOH}$ synthesis. We found out that varying physical parameters of the SDR could fine-tune $\mathrm{Cu}$ NP catalyst sizes using specific chemical recipe. Furthermore, we scaled-up the $\mathrm{Cu}$ NP production for catalytic application in low temperature $\mathrm{MeOH}$ synthesis. 


\section{Results and Discussion}

The SDR technique involves continuous flow of reactant and product stream with short residence time (in seconds) and therefore the process of producing fine nanoparticles must be a fast reaction. In view of this, our $\mathrm{Cu}$ particles were made using borohydride reduction (Equation (5)) [19] which occurs instantaneously when $\mathrm{Cu}^{2+}$ react with $\mathrm{NaBH}_{4}$. Our preliminary test in a flask stirred at $700 \mathrm{rpm}$ showed that when $0.011 \mathrm{M} \mathrm{Cu}^{2+}$ solution was added dropwise to $0.021 \mathrm{M} \mathrm{BH}_{4}{ }^{-}$solution, a black precipitation occurred instantaneously. Figure 1 shows the X-ray diffraction (XRD) and SEM images of $70^{\circ} \mathrm{C}$ oven dried samples. Although $\mathrm{Cu}^{0}$ was the expected product, the oven drying in air easily leads to $\mathrm{Cu}^{0}$ surface oxidation. The XRD and SEM confirmed the formation of $\mathrm{Cu}_{2} \mathrm{O}$ with $9 \pm 1$ and $25 \pm 1$ nm crystallite sizes.

$$
\mathrm{Cu}\left(\mathrm{NO}_{3}\right)_{2}+2 \mathrm{NaBH}_{4}+6 \mathrm{H}_{2} \mathrm{O} \rightarrow \mathrm{Cu} \downarrow+7 \mathrm{H}_{2}+2 \mathrm{NaNO}_{3}+2 \mathrm{~B}(\mathrm{OH})_{3}
$$

The following sections will however focus on the use of the SDR to control Cu particle size. Here, the $\mathrm{Cu}$ salt and borohydride solution comes into contact at a shorter and easily controllable residence time compared with the stirred tank approach described above. The resulting slurry from the SDR was collected in starch to avoid settling and agglomeration of the particles after collection [16,20]. The starch serves as a capping agent to stabilize the $\mathrm{Cu}$ NPs made as well as to prevent further growth of particles.

(a)

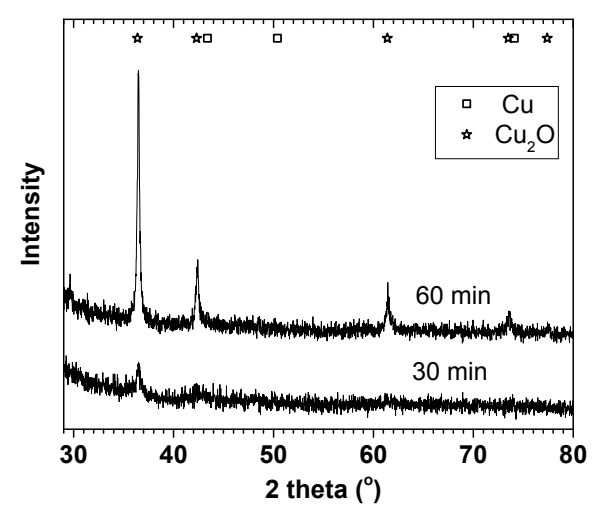

(b)

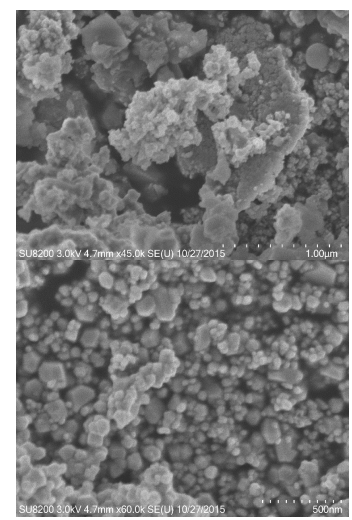

Figure 1. XRD (a) and SEM $((\mathbf{b})=30 \mathrm{~min} \&(\mathbf{c})=60 \mathrm{~min})$ of $\mathrm{Cu}$ NP made in a stirred tank; $0.011 \mathrm{M}$ $\mathrm{Cu}\left(\mathrm{CH}_{3} \mathrm{COO}\right)_{2}$ and $0.021 \mathrm{M} \mathrm{NaBH}_{4}$.

\subsection{Effect of Rotation of Disk Speed and Flow Rate}

Figure 2 shows the effect of the disk rotation speed on particle size distribution (PSD) for a $0.01 \mathrm{M}$ $\mathrm{Cu}\left(\mathrm{NO}_{3}\right)_{2}$ and $0.02 \mathrm{M} \mathrm{NaBH}_{4}$ solution at $5 \mathrm{~mL} / \mathrm{s}$ total flow rate. The faster the rotation, the narrower the PSD, while the mean particle sizes decreased from $35 \pm 2$ to $7.6 \pm 0.5 \mathrm{~nm}$ for the $0.01 \mathrm{M} \mathrm{Cu}\left(\mathrm{NO}_{3}\right)_{2}$, with increasing disk speed from 400 to $2400 \mathrm{rpm}$, respectively. This trend was the same at both 0.01 and $0.05 \mathrm{M} \mathrm{Cu}\left(\mathrm{NO}_{3}\right)_{2}$ starting concentrations. Figure 3 shows the effect of the total flow rate on PSD, at constant $0.02 \mathrm{M} \mathrm{NaBH}_{4}$ flow to $0.01 \mathrm{M} \mathrm{Cu}\left(\mathrm{NO}_{3}\right)_{2}$ flow ratio of 2 and 2400 rpm disk rotation speed. Similarly, mean particle sizes decreased from $14 \pm 1$ to $3.2 \pm 0.2 \mathrm{~nm}$ with narrowing PSD as the flow rate was increased from 3 to $9 \mathrm{~mL} / \mathrm{s}$, respectively. 
(a)

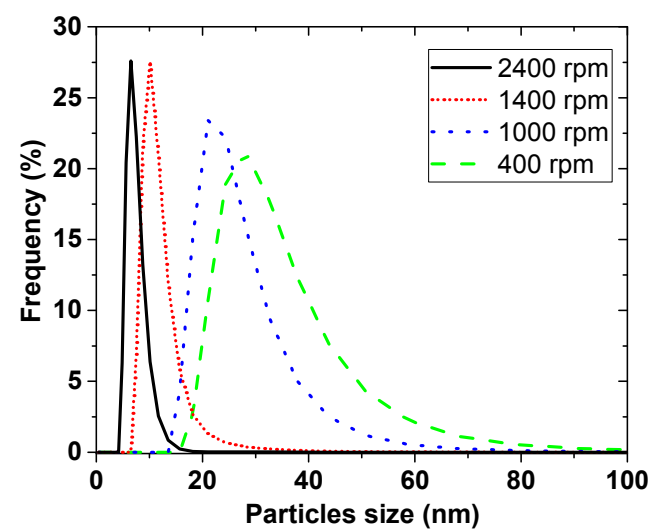

(b)

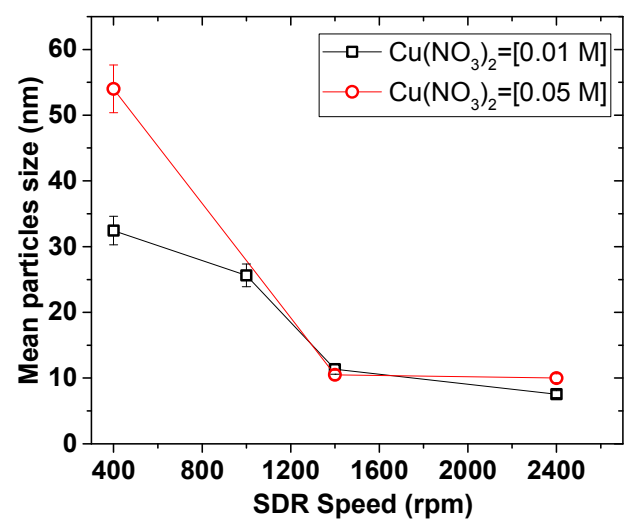

Figure 2. Effect of SDR spinning on (a) PSD for $0.01 \mathrm{MCu}\left(\mathrm{NO}_{3}\right)_{2}$ and (b) mean particle size, at $1.7 \mathrm{~mL} / \mathrm{s}$ of $0.01 \mathrm{M}$ and $0.05 \mathrm{M} \mathrm{Cu}\left(\mathrm{NO}_{3}\right)_{2} ; 3.3 \mathrm{~mL} / \mathrm{s}$ of $0.02 \mathrm{M}$ and $0.10 \mathrm{M} \mathrm{NaBH}_{4}$ (in $0.004 \mathrm{M} \mathrm{NaOH}$ ).

The narrowing of particle size distribution with disk rotation speed and flow rate can be explained by the degree of micromixing achieved under the tested conditions. It is expected that shear effect of thin film formed on the disk and surface wave intensity both increase with increasing disk rotation speed and flow rate $[13,14]$. Mohammadi et al. [13] for example, showed that higher rotation speed and faster flow rate led to shorter micromixing time in the precipitation of titanium hydroxide. This results in more rapid homogeneous mixing at the molecular level coupled with more uniform supersaturation being attained. Short micromixing time favours nucleation over growth [21] leading to small particle formation. Uniformly sized nuclei lead to narrow particle size distribution as observed at high disk rotation speeds and faster flow rates.

(a)

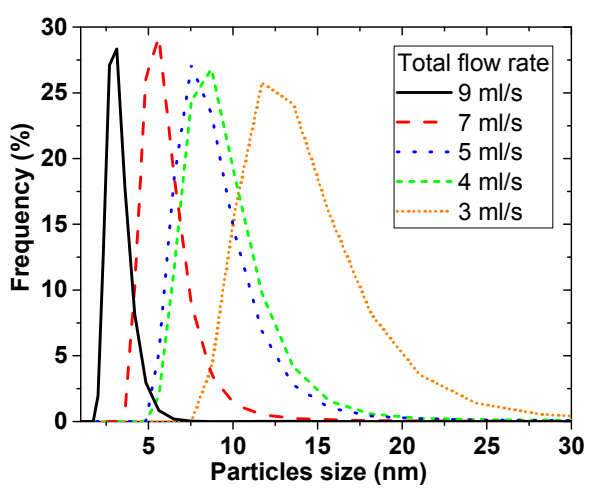

(b)

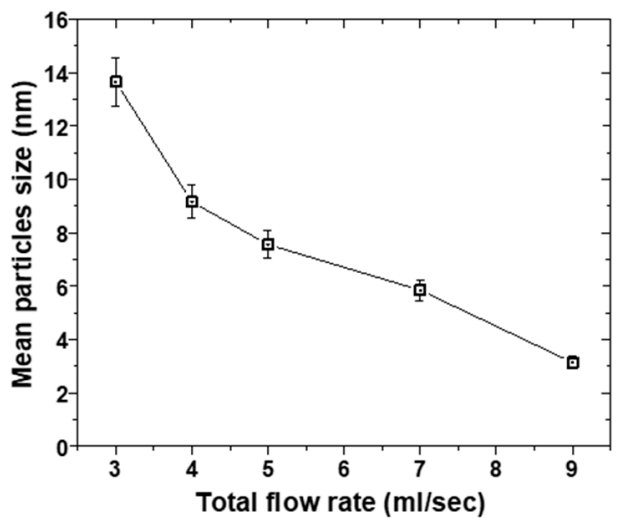

Figure 3. Effect of flow rate on (a) PSD and (b) mean particle size, $0.02 \mathrm{M} \mathrm{NaBH}_{4}$ (in $0.004 \mathrm{M}$ $\mathrm{NaOH}) / 0.01 \mathrm{M} \mathrm{Cu}\left(\mathrm{NO}_{3}\right)_{2}$ flow ratio $=2$, disk speed $=2400 \mathrm{rpm}$.

The SDR mean residence time and its residence time distribution (RTD) also have a significant influence on the final particle size and PSD respectively [13,22-24]. Increasing the rotation speed and flow rate leads to shorter residence time of the nuclei formed on initial contact of the reactants on the disk, thereby limiting the extent of particle growth and agglomeration in the SDR. It is also well-established that under conditions of high disk speeds and high flowrate, the RTD of the film approaches a near plug flow profile [23]. Under a plug flow regime, practically all particles will be subjected to the same mean residence time and processing conditions due to minimal radial dispersion and will exit the disk with a uniform particle size, resulting in tight PSDs. Clearly, the beneficial effects of high disk speeds and reagent flowrates on the film hydrodynamics are wide ranging and have a considerable impact on the formation of $\mathrm{Cu}$ NPs in this work. The best operating conditions are found to be $2400 \mathrm{rpm}$ and $9 \mathrm{~mL} / \mathrm{s}$ total flow rate. 
Figure 4a shows $\mathrm{X}$-ray diffraction of the NPs made at the $0.05 \mathrm{M} \mathrm{Cu}\left(\mathrm{NO}_{3}\right)_{2}$ starting concentration (in Figure 2) oven dried at $70{ }^{\circ} \mathrm{C}$. The XRD showed predominantly $\mathrm{Cu}_{2} \mathrm{O}$ phase with some $\mathrm{Cu}$ phase (plus some $\mathrm{NaNO}_{3}$ reflections). The crystallite sizes estimated using the TOPAS software for the $\mathrm{Cu}_{2} \mathrm{O}$ phase were $10 \pm 1,9.5 \pm 0.7$, and $9.5 \pm 0.5 \mathrm{~nm}$ for 400,1400 , and $2400 \mathrm{rpm}$ respectively. The crystallite sizes were similar for the three rotations despite their particle sizes and distribution differences. Figure $4 \mathrm{~b}$ shows the XRD and TEM image of the NP made at $9 \mathrm{~mL} / \mathrm{s}$ flow rate and $2400 \mathrm{rpm}$ disk speed (in Figure 3). Similarly, $\mathrm{Cu}_{2} \mathrm{O}$ phase was predominant with $4 \pm 1 \mathrm{~nm}$ crystallite size. Furthermore, TEM image of the sample showed about 3-5 nm spherical shaped crystals surrounded by large amorphous materials likely to be the starch used to keep the particles from agglomerating. The XRD and TEM confirmed that $\mathrm{Cu}_{2} \mathrm{O}$ NPs were made in the process with representative PSD as reported using the dynamic light scattering method.

(a)

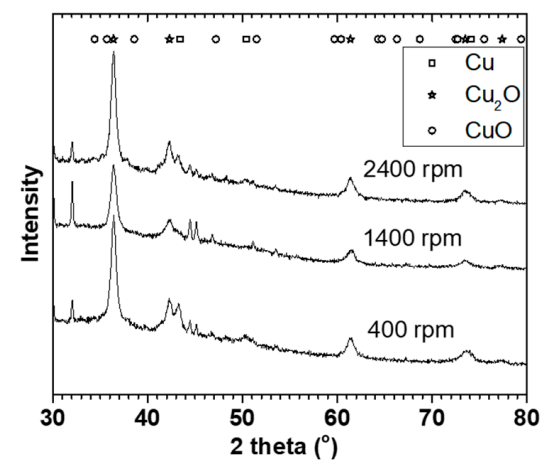

(b)

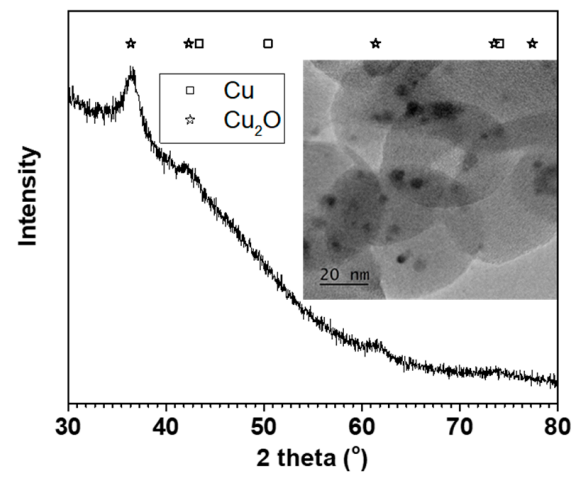

Figure 4. (a) XRD of the $0.05 \mathrm{M} \mathrm{Cu}$ precursor samples in Figure 2b, and (b) XRD with TEM image of the $9 \mathrm{~mL} / \mathrm{s}$ sample in Figure 3.

\subsection{Effect of Rotation Speed on Particles Using Different $\mathrm{Cu}$ Precurors}

Figure 5 shows the effect of the rotation speed on the particles size and PSD of different Cu precursors. Considering the error margin, the three precursors appear to show similar mean particles sizes with a slight distinction at $1400 \mathrm{rpm}$, where $\mathrm{Cu}\left(\mathrm{CH}_{3} \mathrm{COO}\right)_{2}$ gave the smallest particle of $8.1 \mathrm{~nm}$. Nevertheless, the mean particle size decreased and PSD narrowed with the increasing SDR rotation speed. Overall, the mean particle size ranged between $24 \pm 2$ to $6.8 \pm 0.7 \mathrm{~nm}$ with increasing rotation speed. The trend was similar to what was observed and discussed earlier with the $\mathrm{Cu}\left(\mathrm{NO}_{3}\right)_{2}$ precursor. This suggested that the micromixing, residence time, and RTD of the SDR dictated the mean particles and PSD size as discussed earlier rather than the source of the $\mathrm{Cu}$ precursor.

(a)

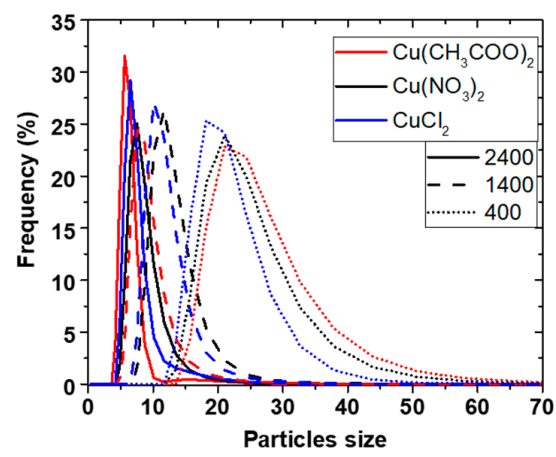

(b)

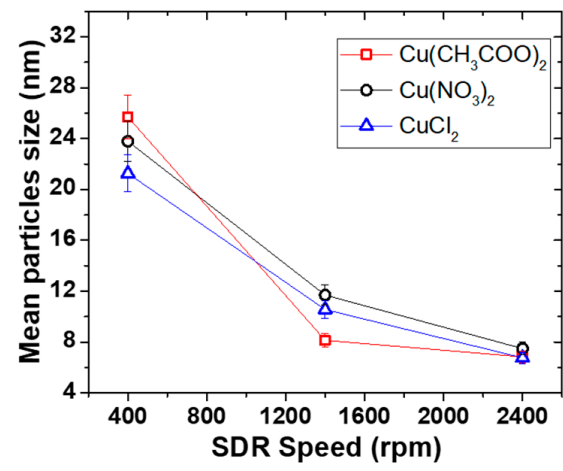

Figure 5. Effect of SDR disk speed on (a) PSD and (b) mean particle size of different Cu precursors, $3 \mathrm{~mL} / \mathrm{s}$ of $0.01 \mathrm{M} \mathrm{Cu}^{2+}$ and $3 \mathrm{~mL} / \mathrm{s}$ of $0.04 \mathrm{M} \mathrm{NaBH}_{4}$ (in $0.004 \mathrm{M} \mathrm{NaOH}$ ). 


\subsection{Effect of Reducing Agent and $p H$ of the Reducing Agent}

Figure 6 shows the effect of the reducing agent on the particle size and PSD. As illustrated in Figure $6 \mathrm{a}$, the mean particle size decreased with reducing flow ratio of $\mathrm{Cu}\left(\mathrm{NO}_{3}\right)_{2} / \mathrm{NaBH}_{4}$ (i.e., increasing $\mathrm{NaBH}_{4}$ flow at the expense of $\mathrm{Cu}\left(\mathrm{NO}_{3}\right)_{2}$ flow), from $17 \pm 1$ to $7.6 \pm 0.5 \mathrm{~nm}$ then the sizes levelled off after ratio of 0.5 . Figure $6 \mathrm{~b}$ illustrates that increasing the concentration of $\mathrm{NaBH}_{4}$ at a constant $\mathrm{Cu}\left(\mathrm{NO}_{3}\right)_{2}$ concentration led to an initial decrease in mean particle sizes, and then levelled off after $0.04 \mathrm{M} \mathrm{NaBH}_{4}$ concentration. However, when $\mathrm{Cu}\left(\mathrm{NO}_{3}\right)_{2}$ and $\mathrm{NaBH}_{4}$ concentration and flow rates were kept constant and the amount of $\mathrm{NaOH}$ was varied, PSD widened and mean particle sizes increased linearly with $\mathrm{pH}$ (Figure 6c).

(a)

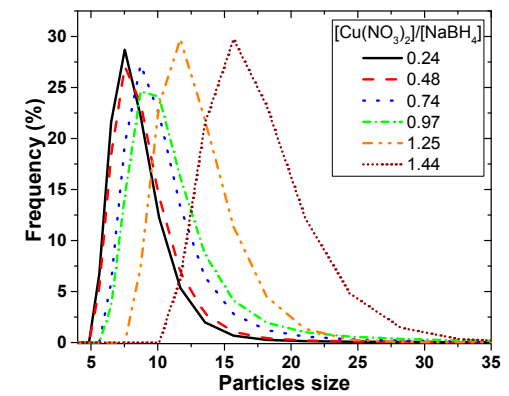

(b)

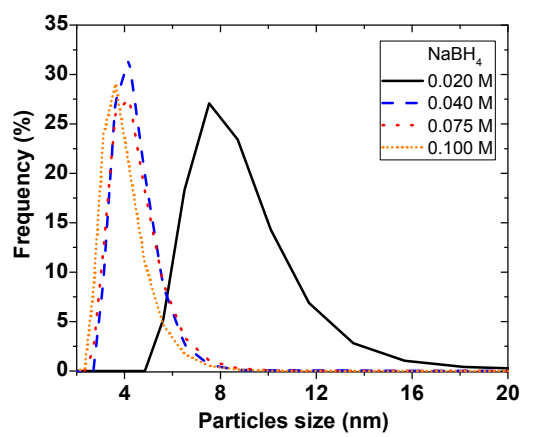

(c)

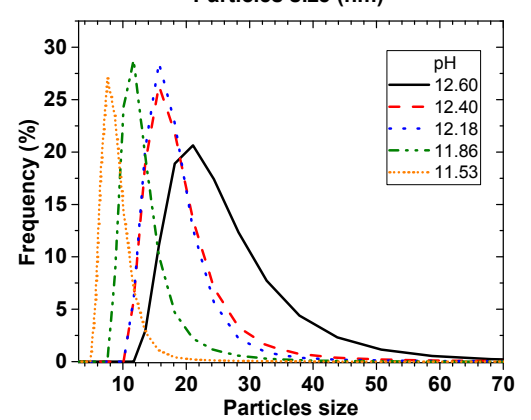

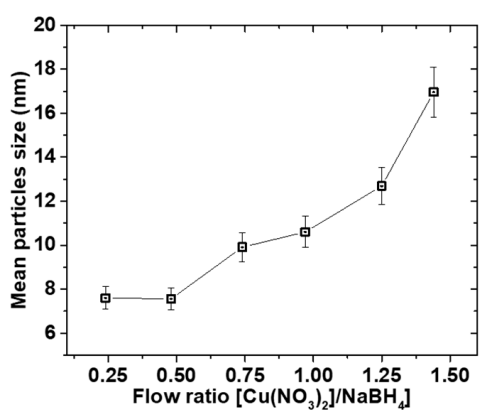
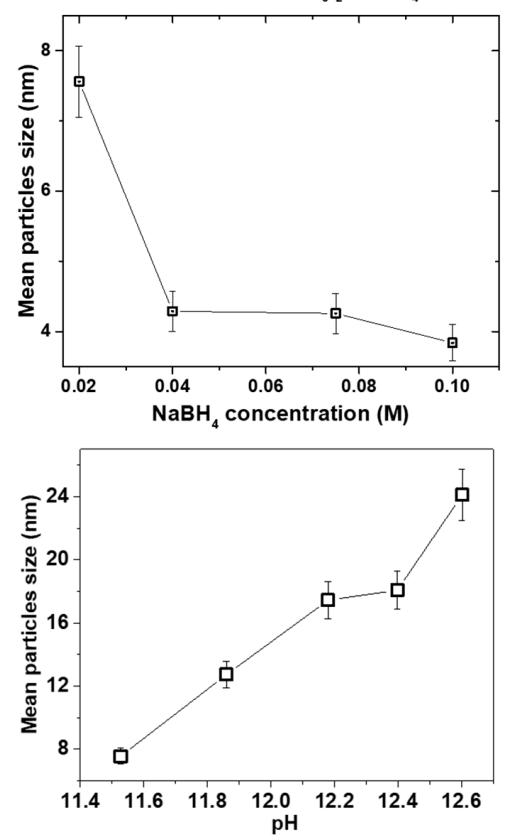

Figure 6. Effect of reducing agent on PSD (left) and mean particle size (right), (a) Effect of flow ratio, (b) Effect of $\mathrm{NaBH}_{4}$ concentration, (c) Effect of $\mathrm{pH}$, (by varying only $\mathrm{NaOH}$ concentrations); $0.01 \mathrm{M}$ $\mathrm{Cu}\left(\mathrm{NO}_{3}\right)_{2}, 0.02 \mathrm{M} \mathrm{NaBH}_{4}$ (in $0.004 \mathrm{M} \mathrm{NaOH}$ ), at $2400 \mathrm{rpm}$ disk speed, $5 \mathrm{~mL} / \mathrm{s}$ total flow rate.

Equation (5) showed that the $\mathrm{Cu}^{2+}$ reduction involves $\mathrm{NaBH}_{4}$ hydrolysis. Since $\mathrm{NaBH}_{4}$ is both soluble and reactive in water, $\mathrm{NaOH}$ was added to keep the $\mathrm{NaBH}_{4}$ in solution for the reduction process. It has been reported that the rate of $\mathrm{NaBH}_{4}$ hydrolysis increases with decreasing $\mathrm{pH}$ [25]. Ingersoll et al. [26] also reported that the amount of hydrolysis of $\mathrm{NaBH}_{4}$ can be enhanced catalytically, such that in the presence of $\mathrm{NiCl}_{2}$ and $\mathrm{CoCl}_{2}$ salts, the rate of hydrolysis decreased with increasing $\mathrm{NaOH}$ concentration. Considering the relatively short residence time for the reagents on the SDR, any factor that affects the reactivity and accessibility of the $\mathrm{BH}_{4}{ }^{-}$can have consequence on the precipitation reaction to affect the particle size and PSD. This was evident when particle size linearly increased with pH (Figure $6 \mathrm{c}$ ) as the amount of $\mathrm{OH}^{-}$increased supressing the reactivity of the $\mathrm{NaBH}_{4}$. 
Furthermore, the stoichiometry of the reaction (Equation (5)) requires that the amount of $\mathrm{NaBH}_{4}$ should be more than the $\mathrm{Cu}\left(\mathrm{NO}_{3}\right)_{2}$ to reduce all the $\mathrm{Cu}$ precursor towards precipitation. When $\mathrm{NaBH}_{4}$ becomes the limiting reagent, the amount of reactive $\mathrm{NaBH}_{4}$ readily available for the $\mathrm{Cu}^{2+}$ reduction is decreased, thereby increasing the time to attain homogeneity of the mixture. Subsequently, this leads to less uniform nuclei formation and there is delay in adequate micromixing, leading to patchy growth Considering the short retention time involved in the process, wider PSD with bigger particles occurs as the amount of $\mathrm{NaBH}_{4}$ decreased. On the other hand, when the amount of $\mathrm{NaBH}_{4}$ increases to a certain maximum (for e.g., $0.04 \mathrm{M} \mathrm{BH}_{4}{ }^{-}: 0.01 \mathrm{M} \mathrm{Cu}^{2+}$ ), the relative increase in reactive $\mathrm{NaBH}_{4}$ reaches a saturation point and all the $\mathrm{Cu}$ reacts with $\mathrm{NaBH}_{4}$ in a shorter time such that excess $\mathrm{NaBH}_{4}$ will have no further effect.

\subsection{Scaling up Cu NP Production and Methanol Synthesis}

To apply the $\mathrm{Cu} \mathrm{NP}$ as catalyst for $\mathrm{MeOH}$ synthesis, a larger amount of NP production was required over a longer continuous processing time. Firstly, $1 \mathrm{~L}$ of different starting $\mathrm{Cu}\left(\mathrm{NO}_{3}\right)_{2}$ concentrations were used at a $2400 \mathrm{rpm}$ rotation speed and $1 \mathrm{Cu}\left(\mathrm{NO}_{3}\right)_{2}: 2 \mathrm{NaBH}_{4}$ flow rate. Figure $7 \mathrm{a}, \mathrm{b}$ shows the PSD and X-ray diffraction for $0.01,0.025$, and $0.050 \mathrm{M}$ starting $\mathrm{Cu}\left(\mathrm{NO}_{3}\right)_{2}$ concentrations. The mean particle sizes increased from $7.6 \pm 0.5$ to $22 \pm 2 \mathrm{~nm}$ and the PSD widened when the $\mathrm{Cu}\left(\mathrm{NO}_{3}\right)_{2}$ concentration was increased. Separation of the NP from solution was challenging and we resorted to oven drying at $90{ }^{\circ} \mathrm{C}$. Mainly $\mathrm{Cu}_{2} \mathrm{O}$ and $\mathrm{Cu}$ crystallite (+ some $\mathrm{NaNO}_{3}$ phase) were observed and the crystallite sizes slightly increased from $8.6 \pm 0.2$ to $10.8 \pm 0.3 \mathrm{~nm}$ with increasing concentration even though the mean particle sizes were generally larger. A similar observation was made by Chang et al. [17] where mean particle size increased from 48.3 to $93.0 \mathrm{~nm}$ when $\mathrm{Cu}\left(\mathrm{SO}_{4}\right)_{2}$ concentration was increased from 0.01 to $0.40 \mathrm{M}$. As concentration increased, the probability of nuclei colliding with each other increased leading to agglomeration and larger particles size as well as wider PSD.

Figure 7c shows the TEM image and electron diffraction of the $\mathrm{Cu} N P$ made at $0.01 \mathrm{M} \mathrm{Cu}\left(\mathrm{NO}_{3}\right)_{2}$ starting concentration. The spherical shaped polycrystalline $\mathrm{Cu}_{2} \mathrm{O}$ observed in the TEM image, which showed particle sizes around $10 \mathrm{~nm}$, confirmed that the method can be scaled-up. The challenge however, is the separation of the particles from the starch, as the starch gelatine used was no more soluble in water. Given that the resulting slurry was colloidal in nature, it was difficult to use a centrifuge to isolate the NPs. As a result, the slurry was dried at $90^{\circ} \mathrm{C}$, which could lead to possible increase in agglomeration of particles. If the reaction were carried out in solvent of interest for further processes or the catalysis in our case, then there would not be any need for separation or drying. However, our equipment at the time of this study was not materially compatible with ether solvents and we resorted to the use of water as a solvent.

(a)

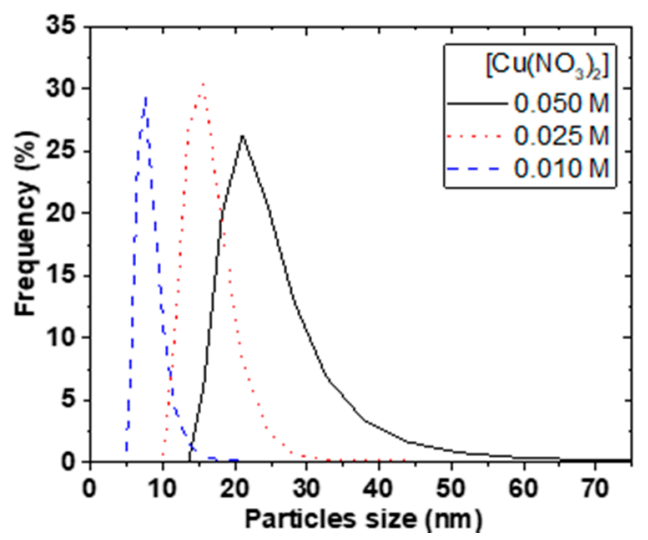

(b)

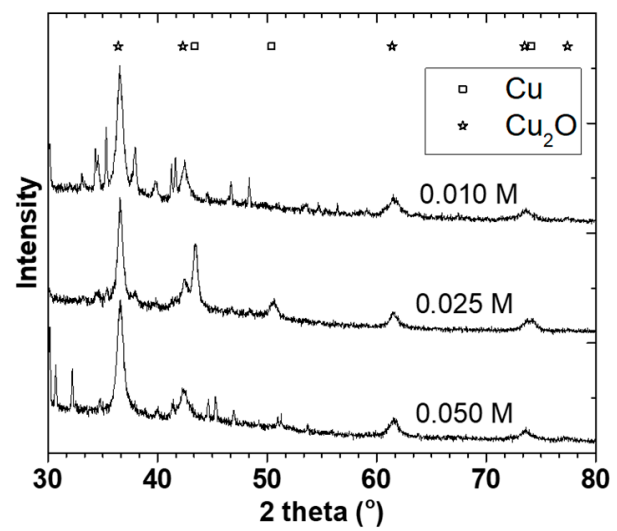

Figure 7. Cont. 
(c)

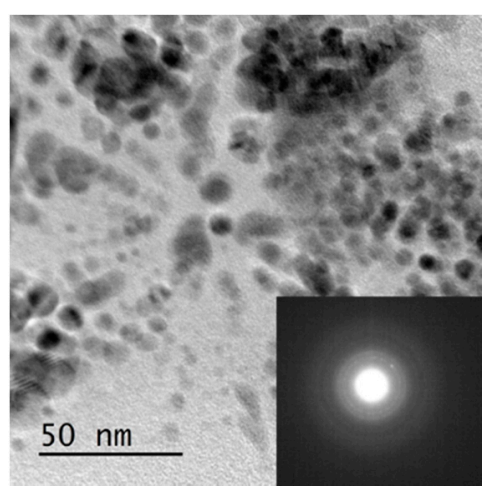

Figure 7. Effect of $\mathrm{Cu}\left(\mathrm{NO}_{3}\right)_{2}$ concentration on $\mathrm{NP}$, (a) Effect of concentration on PDS, (b) XRD of the dried samples, (c) TEM image and diffraction of the dried $0.01 \mathrm{M}$ sample; at $2400 \mathrm{rpm}$, $1 \mathrm{Cu}^{2+}: 4 \mathrm{BH}_{4}{ }^{-}$concentration, $9 \mathrm{~mL} / \mathrm{s}$ flow.

Furthermore, based on our knowledge of controlling $\mathrm{Cu}$ NP from the above, three tailored $\mathrm{Cu}$ NP with different mean particle sizes collected in starch were used for $\mathrm{MeOH}$ synthesis. Figure 8 shows XRD and TEM characterization for some $90^{\circ} \mathrm{C}$ oven dried samples. These particles were spherical and polycrystalline, with mainly $\mathrm{Cu}_{2} \mathrm{O}$ and $\mathrm{Cu}^{0}$ phases. The crystallite sizes were $8.6 \pm 0.5,9.0 \pm 0.6$, and $9.5 \pm 0.7 \mathrm{~nm}$ with $21 \pm 1,26 \pm 2$ and $29 \pm 2 \mathrm{~nm}$ particles sizes for B1 S, B $4 \mathrm{~S}$, and B 5 S respectively ( $\mathrm{S}=$ with starch, see Figure 9 ). In addition, for comparison, B1 was repeated without starch (NS), where $\mathrm{CuO}$ was the predominant phase with $9.4 \pm 0.7 \mathrm{~nm}$ crystallite and $38 \pm 2 \mathrm{~nm}$ mean particle sizes. This suggested that aside from reducing agglomeration of the particles, the starch also reduced the amount of surface oxidation of the resulting NPs.

Syngas conversion over the selected samples ranged from about $50 \%$ to $70 \%$ conversion per batch, which is around the same range achieved in other $\mathrm{Cu}$-alkoxide systems [8,27]. However, for comparison reasons, the amount of $\mathrm{MeOH}$ produced per amount of $\mathrm{Cu}(\mathrm{in} \mathrm{mol} /(\mathrm{mol} \cdot \mathrm{h})$ ) is presented. Figure 9 shows the $\mathrm{MeOH}$ productivity compared with particle sizes. The $\mathrm{MeOH}$ productivity generally increased with decreasing particles sizes. This has already been attributed to the increase in total surface area as particle sizes decreased $[7,10]$.

(a)

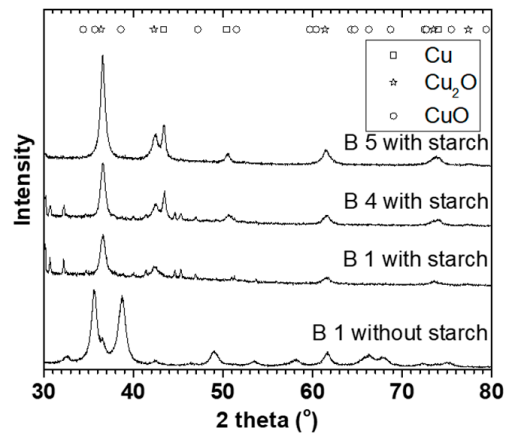

(b)

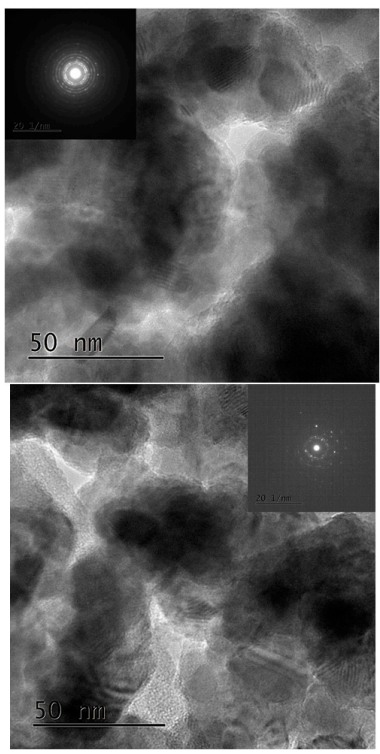

Figure 8. Scale-up $\mathrm{Cu} N \mathrm{NP}$ for $\mathrm{MeOH}$ synthesis, $\mathrm{S}=$ in starch, NS = No starch, (a) XRD, (b) TEM image of B 4S, (c) TEM image of B 5 S. 
The B1 NS sample showed a higher $\mathrm{MeOH}$ productivity than all the smaller particles collected in the starch. This sample differed from the other starch containing specimens by particle size and $\mathrm{Cu}$ phases present. Previous results have shown that in the presence of $20 \mathrm{bar} \mathrm{CO} / 2 \mathrm{H}_{2}$ at $100{ }^{\circ} \mathrm{C}$, reduction of $\mathrm{Cu}^{2+}$ is rapid $[10,28]$, and that the active $\mathrm{Cu}$ phase for the $\mathrm{MeOH}$ synthesis is assumed to be in the $\mathrm{Cu}^{+} / \mathrm{Cu}^{\circ}$ oxidation state [29]. This implies that it is not likely that the $\mathrm{Cu}$ phase in the B 1 NS catalyst contributed to the difference in the activity but rather the absence of starch. Hence, the lower activity of the catalyst samples containing starch could be due to mass transfer limitations of the substrate in accessing the surface of the $\mathrm{Cu}$ NP. This is in contrast to the B 1 NS catalyst where no starch is present on the surface. Nevertheless, the scaled-up Cu materials made with the SDR were active for $\mathrm{MeOH}$ synthesis either with or without starch present and can be further explored for optimization.

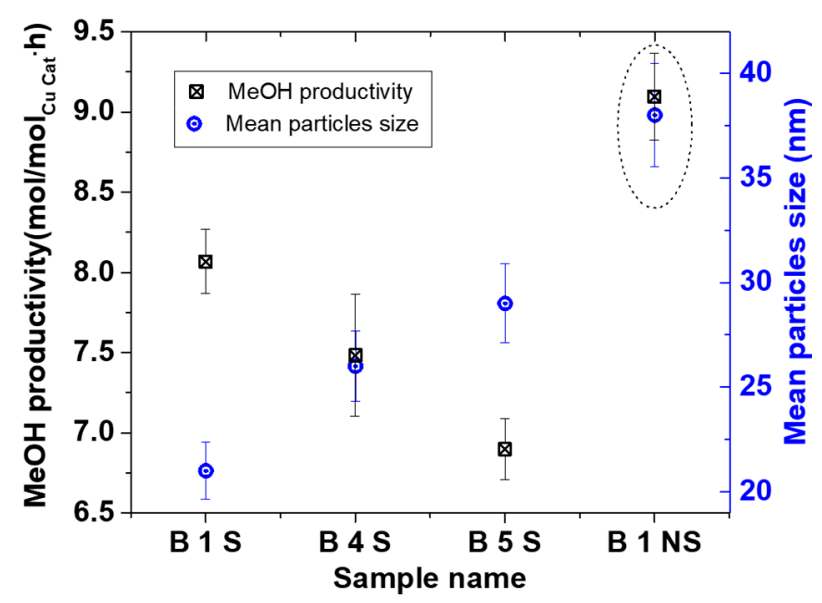

Figure 9. Low temperature $\mathrm{MeOH}$ synthesis of scale-up $\mathrm{Cu} \mathrm{NP} ; 2 \mathrm{H}_{2} / \mathrm{CO}=20$ bar, $\mathrm{THF}$ solvent $=30 \mathrm{~mL}$, for $\mathrm{MeOH}$ synthesis.

\section{Materials and Methods}

\subsection{Spinning Disk Reactor}

The set-up used in this work is shown in the schematic diagram in Figure 10 similar to the one described elsewhere $[13,14]$. The $10 \mathrm{~cm}$ diameter smooth surfaced stainless steel disk was driven by a $125 \mathrm{~W}$ electric motor, coupled with a digitally controlled rotating disk. A temperature controlled water-bath was circulated beneath the disk to ensure constant disk temperature (at $\left.25{ }^{\circ} \mathrm{C}\right) \cdot \mathrm{Cu}\left(\mathrm{NO}_{3}\right)_{2}$ solution in one line and $\mathrm{NaBH}_{4}$ dissolved in $\mathrm{NaOH}$ solution in another line were fed onto the centre of the spinning disk. A Watson Marlow 323 peristaltic pump coupled with a dampener at the discharge end was used to control smooth flow of the two reagents. Each feed tube made of Viton, with $3.2 \mathrm{~mm}$ hole ends was set at a distance $6 \mathrm{~mm}$ perpendicular to the centre of the spinning disk. The reaction was carried out in a $\mathrm{N}_{2}$ blanket to minimize direct contact of the reaction with air.

As shown in the Equation (5), $\mathrm{Cu}$ particles were precipitated by borohydride reduction. Typically, 0.01-0.05 $\mathrm{M}$ standard solutions of $\mathrm{Cu}\left(\mathrm{NO}_{3}\right)_{2}$ was reacted with $0.02-0.20 \mathrm{M} \mathrm{NaBH}$ dissolved in about $17 w / w \% \mathrm{NaOH}$. Since $\mathrm{NaBH}_{4}$ is both soluble and reactive in water, adding the $\mathrm{NaOH}$ was necessary to keep $\mathrm{NaBH}_{4}$ in solution. To avoid agglomeration and settling of the particles after collection from the SDR, samples were collected in starch as has been used elsewhere [16]. Thus, the resulting product was collected in $1 \mathrm{wt} \%$ starch gelatine solution. The starch gelatine was prepared by dissolving $10 \mathrm{~g}$ starch in $1000 \mathrm{~mL}$ water heated to $90^{\circ} \mathrm{C}$. The influence of starch on the particle size distribution for a period is shown in the supplementary material Figure $S 1$. 


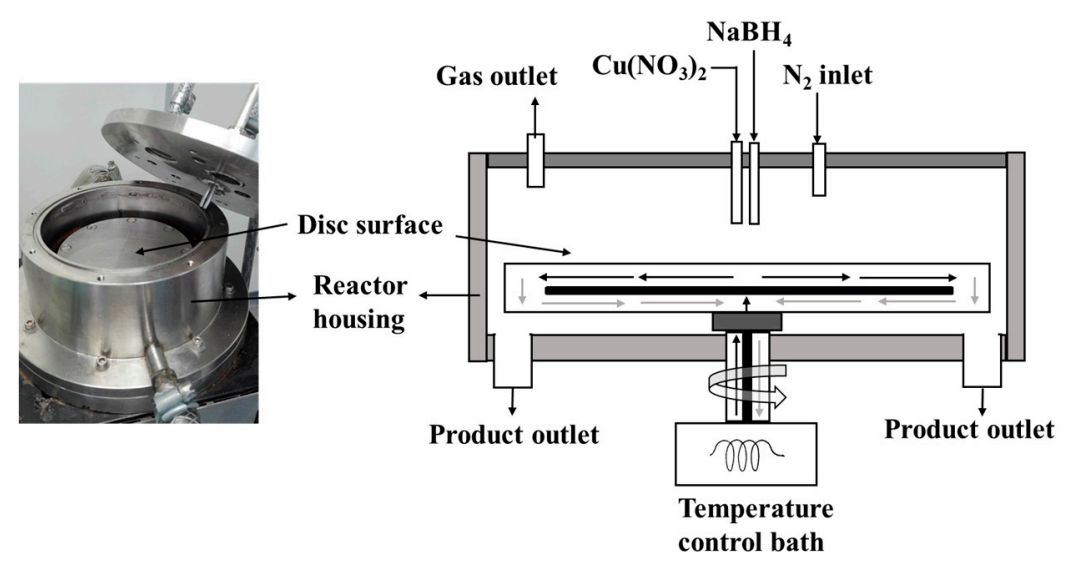

Figure 10. Scheme of SDR set-up used in making Cu NP.

\subsection{Characterization of $\mathrm{Cu}$ Nanoparticles and Methanol Synthesis}

Mean particle sizes and particles size distributions were analysed using dynamic light scattering (Malvern instrument, Model HPPS) with a He-Ne laser as light source $(\lambda=633 \mathrm{~nm})$ and measured at $25{ }^{\circ} \mathrm{C}$. Samples to be used for $\mathrm{MeOH}$ synthesis were dried at $90{ }^{\circ} \mathrm{C}$ for further characterization. A Bruker D8 discover powder diffractometer using Cu K- $\alpha-1$ radiation $(\lambda=1.5 \AA)$ selected by a Ge (111) Johansen monochromator and a Lynxeye detector were used. The diffractogram was measured at $0.025^{\circ}$ steps per second. Total Pattern Analysis Solution (TOPAS) software was employed for quantitative Rietveld analysis of the diffractogram. This software operates by fitting a theoretical diffraction pattern to a measured diffraction pattern using non-linear least square algorithms [30]. The SEM imaging was performed using SU8230 ultra-high resolution cold-field emission SEM from Hitachi. The TEM imaging was performed with a Joel 2100F instrument. Diluted samples were dispersed in an ultrasound bath for $30 \mathrm{~min}$ and then deposited onto a carbon film on a copper grid.

$\mathrm{MeOH}$ synthesis was done similar to the process described in [10,31] in a $200 \mathrm{~mL}$ stainless high pressure hpm-020 autoclave batch reactor (Premex Reactor AG), equipped with a pressure sensor and thermocouple inserted. Weighed $\mathrm{Cu} N \mathrm{NP}$ and sodium methoxide $\left(\mathrm{NaCHO}_{3}\right)$ were added to $50 \mathrm{~mL}$ diglyme placed in the reactor. The reactor was charged to about 20 bar syngas $\left(1 \mathrm{CO}: 2 \mathrm{H}_{2}\right)$, then stirred at $3000 \mathrm{rpm}$ and heated to $100{ }^{\circ} \mathrm{C}$. The cooled liquid products were analysed using Agilent $7890 \mathrm{~A}$ GC with Agilent 7683B autosampler coupled with Agilent 5975 mass spectrometer detector (MSD). A CARBOWAX 007 series $20 \mathrm{M}$ column with dimensions $60 \mathrm{~m} \times 320 \mu \mathrm{m} \times 1.2 \mu \mathrm{m}$ was used and programmed at $15{ }^{\circ} \mathrm{C} / \mathrm{min}$ temperature ramp from $40{ }^{\circ} \mathrm{C}$ to $200{ }^{\circ} \mathrm{C}$ and held at $200{ }^{\circ} \mathrm{C}$ for $3 \mathrm{~min}$, at $0.47 \mathrm{bar}(6.8 \mathrm{psi})$ constant pressure. $0.54 \mathrm{mg}$ heptane was as an internal standard.

Dry powdery sample was used for most of the characterization (XRD and TEM) and $\mathrm{MeOH}$ synthesis. Given that the collected sample from the SDR was colloidal in nature when collected in starch, it was difficult to use centrifuge for isolating the Cu NP. Slurry samples in smaller proportions were oven dried at $90{ }^{\circ} \mathrm{C}$ overnight. The dry samples were used for the $\mathrm{MeOH}$ synthesis without purification. $\mathrm{MeOH}$ productivity was calculated as shown in Equation (6).

$$
\text { Productivity }=\frac{\text { amount of } \mathrm{MeOH}(\mathrm{mol})}{\text { amount of } C u_{\text {catalyst }}(\mathrm{mol}) \times \text { reaction time }(\mathrm{h})}
$$

\section{Conclusions}

The SDR was used for making varying copper NP sizes based on copper borohydride reduction reaction. The $\mathrm{Cu}$ NP sizes and distributions were varied by changing physical and chemical parameters involved in the precipitation reaction. Particle size distribution narrowed with a corresponding decrease in particle size when micro-mixing time was shortened by, for example, increasing SDR rotation speed and total flow rates. Particle sizes in the range of 3 to $55 \mathrm{~nm}$ were obtained, which upon 
oven drying at 70 or $90^{\circ} \mathrm{C}$ showed predominantly polycrystalline $\mathrm{Cu}_{2} \mathrm{O}$ and $\mathrm{Cu}$ phases. The advantage of the current technique is that it provides a faster approach to fine tuning $\mathrm{Cu} N \mathrm{~N}$ sizes for $\mathrm{MeOH}$ synthesis by varying physical parameters but using the same chemical recipe. The NPs were tested to be active for $\mathrm{MeOH}$ synthesis at low temperature $\left(100^{\circ} \mathrm{C}\right)$ and $\mathrm{MeOH}$ productivity increased with decreasing particle sizes.

Supplementary Materials: The following are available online at www.mdpi.com/1996-1944/11/1/154/s1, Figure S1: Effect of starch concentration on PSD.

Acknowledgments: This work was funded by the Research Council of Norway, NFR project number 228157/O70. We acknowledge that part of the work was carried out at RECX (the Norwegian national resource centre for X-ray diffraction and scattering) and NorTEM (the Norwegian Centre for Transmission Electron Microscopy) both in Oslo.

Author Contributions: Christian Ahoba-Samv, Unni Olsbye, and Klaus-Joachim Jens conceived the idea, Christian Ahoba-Samv and Kamelia V. K. Boodhoo designed the experiment; Christian Ahoba-Samv performed the experiments and drafted the work; Christian Ahoba-Samv, Unni Olsbye, Klaus-Joachim Jens, and Kamelia V. K. Boodhoo analysed and interpreted the data, revised the final version, and gave their approval for submission.

Conflicts of Interest: The authors declare no conflict of interest.

\section{References}

1. Olah, G.A. Beyond Oil and Gas: The Methanol Economy. Angew. Chem. Int. Ed. 2005, 44, $2636-2639$. [CrossRef] [PubMed]

2. Olsbye, U.; Svelle, S.; Bjørgen, M.; Beato, P.; Janssens, T.V.; Joensen, F.; Bordiga, A.; Lillerud, K.P. Conversion of Methanol to Hydrocarbons: How Zeolite Cavity and Pore Size Controls Product Selectivity. Angew. Chem. Int. Ed. 2012, 51, 5810-5831. [CrossRef] [PubMed]

3. Hansen, J.B.; Højlund Nielsen, P.E. Methanol Synthesis. In Handbook of Heterogeneous Catalysis; Ertl, G., Knözinger, H., Weikamp, J., Eds.; Wiley-VCH Verlag GmbH \& Co. KGaA: Weinheim, Germany, 2008; pp. 2920-2949.

4. Marchionna, M.; Di Girolamo, M.; Tagliabue, L.; Spangler, M.J.; Fleisch, T.H. A review of low temperature methanol synthesis. Stud. Surf. Sci. Catal. 1998, 119, 539-544.

5. Schiffer, Z.J.; Manthiram, K. Electrification and Decarbonization of the Chemical Industry. Joule 2017, 1, 10-14. [CrossRef]

6. Christiansen, J.A. Method of Producing Methyl Alcohol. U.S. Patent 1,302,011, 29 April 1919.

7. Ohyama, S.; Kishida, H. Physical mixture of $\mathrm{CuO}$ and $\mathrm{Cr}_{2} \mathrm{O}_{3}$ as an active catalyst component for low-temperature methanol synthesis via methyl formate. Appl. Catal. A Gen. 1998, 172, 241-247. [CrossRef]

8. Li, B.; Jens, K.-J. Low-Temperature and Low-Pressure Methanol Synthesis in the Liquid Phase Catalyzed by Copper Alkoxide Systems. Ind. Eng. Chem. Res. 2013, 53, 1735-1740. [CrossRef]

9. Xing-Quan, L.; Wu, Y.; Luo, S.; Yang, Y.; Jia, Z.; Li, S.; Chen, W.; Yu, Z. Concurrent Synthesis of Methanol and Methyl Formate Catalysed by Copper-based catalysts II. Influences of solvents and $\mathrm{H}_{2} / \mathrm{CO}$ mole ratios. J. Nat. Gas Chem. 1999, 8, 203-210.

10. Ahoba-Sam, C.; Olsbye, U.; Jens, K.-J. Low temperature methanol synthesis catalyzed by copper nanoparticles. Catal. Today 2018, 299, 112-119. [CrossRef]

11. Ohyama, S.; Kishida, H. XRD, HRTEM and XAFS studies on structural transformation by milling in a mixture of $\mathrm{CuO}$ and $\mathrm{Cr}_{2} \mathrm{O}_{3}$ as an active catalyst component for low-temperature methanol synthesis. Appl. Catal. A Gen. 1999, 184, 239-248. [CrossRef]

12. Gawande, M.B.; Goswami, A.; Felpin, F.X.; Asefa, T.; Huang, X.; Silva, R.; Zou, X.; Zboril, R.; Varma, R.S. $\mathrm{Cu}$ and $\mathrm{Cu}$-Based Nanoparticles: Synthesis and Applications in Catalysis. Chem. Rev. 2016, 116, 3722-3811. [CrossRef] [PubMed]

13. Mohammadi, S.; Harvey, A.; Boodhoo, K.V.K. Synthesis of $\mathrm{TiO}_{2}$ nanoparticles in a spinning disc reactor. Chem. Eng. J. 2014, 258, 171-184. [CrossRef]

14. Boodhoo, K.V.K.; Al-Hengari, S.R. Micromixing Characteristics in a Small-Scale Spinning Disk Reactor. Chem. Eng. Technol. 2012, 35, 1229-1237. [CrossRef]

15. Boodhoo, K. Spinning Disc Reactor for Green Processing and Synthesis. In Process Intensification for Green Chemistry; John Wiley \& Sons, Ltd.: Chichester, UK, 2013; pp. 59-90. 
16. Tai, C.Y.; Wang, Y.-H.; Liu, H.-S. A green process for preparing silver nanoparticles using spinning disk reactor. AIChE J. 2008, 54, 445-452. [CrossRef]

17. Chang, M.-H.; Liu, H.-S.; Tai, C.Y. Preparation of copper oxide nanoparticles and its application in nanofluid. Powder Technol. 2011, 207, 378-386. [CrossRef]

18. He, F.; Zhao, D. Preparation and Characterization of a New Class of Starch-Stabilized Bimetallic Nanoparticles for Degradation of Chlorinated Hydrocarbons in Water. Environ. Sci. Technol. 2005, 39, 3314-3320. [CrossRef] [PubMed]

19. Glavee, G.N.; Klabunde, K.J.; Sorensen, C.M.; Hadjipanayis, G.C. Borohydride Reduction of Nickel and Copper Ions in Aqueous and Nonaqueous Media. Controllable Chemistry Leading to Nanoscale Metal and Metal Boride Particles. Langmuir 1994, 10, 4726-4730. [CrossRef]

20. Bashir, O.; Hussain, S.; AL-Thabaiti, S.A.; Khan, Z. Synthesis, optical properties, stability, and encapsulation of Cu-nanoparticles. Spectrochim. Acta Part A Mol. Biomol. Spectrosc. 2015, 140 (Suppl. C), 265-273. [CrossRef] [PubMed]

21. Leubner, I.H. Particle nucleation and growth models. Curr. Opin. Colloid Interface Sci. 2000, 5, 151-159. [CrossRef]

22. Bałdyga, J.; Pohorecki, R. Turbulent micromixing in chemical reactors-A review. Chem. Eng. J. Biochem. Eng. J. 1995, 58, 183-195. [CrossRef]

23. Mohammadi, S.; Boodhoo, K.V.K. Online conductivity measurement of residence time distribution of thin film flow in the spinning disc reactor. Chem. Eng. J. 2012, 207-208 (Suppl. C), 885-894. [CrossRef]

24. Ghiasy, D.; Tham, M.T.; Boodhoo, K.V.K. Control of a Spinning Disc Reactor: An Experimental Study. Ind. Eng. Chem. Res. 2013, 52, 16832-16841. [CrossRef]

25. Mesmer, R.E.; Jolly, W.L. The Hydrolysis of Aqueous Hydroborate. Inorg. Chem. 1962, 1, 608-612. [CrossRef]

26. Ingersoll, J.C.; Mani, N.; Thenmozhiyal, J.C.; Muthaiah, A. Catalytic hydrolysis of sodium borohydride by a novel nickel-cobalt-boride catalyst. J. Power Sources 2007, 173, 450-457. [CrossRef]

27. Li, B.; Jens, K. Liquid-Phase Low-Temperature and Low-Pressure Methanol Synthesis Catalyzed by a Raney Copper-Alkoxide System. Top. Catal. 2013, 56, 725-729. [CrossRef]

28. Fleisch, T.H.; Mieville, R.L. Studies on the chemical state of Cu during methanol synthesis. J. Catal. 1984, 90, 165-172. [CrossRef]

29. Liu, H.; Chen, T.; Yang, G.; Wang, G.Y. Investigation of Active Center of Cu-Based Catalyst for Low Temperature Methanol Synthesis from Syngas in Liquid Phase: The Contribution of $\mathrm{Cu}^{+}$and $\mathrm{Cu}^{0}$. ChemistrySelect 2017, 2, 8000-8007. [CrossRef]

30. TOPAS. Available online: https://www.bruker.com/products/x-ray-diffraction-and-elemental-analysis/xray-diffraction/xrd-software/topas/rietveld-analysis-software.html (accessed on 28 October 2016).

31. Ahoba-Sam, C.; Olsbye, U.; Jens, K.-J. The Role of Solvent Polarity on Low-Temperature Methanol Synthesis Catalyzed by Cu Nanoparticles. Front. Energy Res. 2017, 5. [CrossRef] 